\title{
Itinerários possíveis da política de assistência social: garantia de direitos e governamentalidade
}

\section{Possible routes of social assistance policy: guarantee of rights and governmentality}

\section{Posibles itinerarios de la política de asistencia social: la ga- rantía de los derechos y la gobernabilidad}

\section{Karen Cristina Cavagnoli*}

Universidade Federal do Rio Grande do Sul - UFRGS, Porto Alegre, Rio Grande do Sul, Brasil

\section{Neuza Maria de Fátima Guareschi**}

Universidade Federal do Rio Grande do Sul - UFRGS, Porto Alegre, Rio Grande do Sul, Brasil

\begin{abstract}
RESUMO
O artigo discute as práticas de garantia de direitos partindo da análise da Política Nacional de Assistência Social e os programas sociais vinculados às práticas de assistência - Bolsa Família e Paif- Programa de Atendimento Integral à Família, na perspectiva do que Foucault denomina como tecnologias de governo da população. Problematiza-se que o Estado faz operar um jogo entre garantia de direitos e controle sobre as famílias consideradas em vulnerabilidade social. Aponta-se que a proteção social enunciada na política não é somente possibilidade de acesso aos direitos, mas uma forma de gerenciamento de riscos por meio de intervenções centradas na família, que contribuem para um processo de privatização das problemáticas sociais.
\end{abstract}

Palavras-chave: assistência social, garantia de direitos, risco, governamentalidade.

\section{ABSTRACT}

The article discusses the rights assurance practices based on the analysis of the National Policy of Social Welfare and social programs related to care practices - Bolsa Família and Paif- Programa de Atendimento Integral à Família, in the light of what Foucault called as technologies of population government. It discusses that the State, in its inability to distribute power, makes operate a game between the guarantee of rights and control over families considered socially vulnerable. It points out that social protection stated in the policy is not only expression and the possibility of access to rights, but a form of risk management through interventions focused on the family, contributing to a process of privatization of social problems.

Keywords: social assistance, rights guarantees, risk, governmentality. 


\section{RESUMEN}

El presente artículo discute las prácticas de garantía de derechos a partir del análisis de la Política Nacional de Assistência Social (Política Nacional de Asistencia Social) y los programas sociales vinculados a las prácticas de asistencia - Bolsa Família y Paif- Programa de Atendimento Integral à Família (Programa de Atención Integral a la Familia), en la perspectiva que Foucault denomina como tecnologías de gobierno de la población. Se problematiza que el Estado, en su incapacidad de distribuir poder, hace operar un juego entre garantía de derechos y control sobre las familias consideradas en vulnerabilidad social. Se apunta que la protección social enunciada en la política no es solamente expresión y posibilidad de acceso a los derechos, sino que una forma de gerenciamiento de riesgos por medio de intervenciones centradas en la familia, que contribuye para un proceso de privatización de las problemáticas sociales.

Palabras clave: asistencia social, garantías de los derechos, riesgo, gubernamentalidad.

\section{Entrelaçamentos entre vida e política: introduzindo um campo problemático}

O Estado, na forma como está constituído, é o resultado do embate de interesses de poder e lutas sociais travadas até então e que tem como um de seus instrumentos suas políticas públicas, que podem ser entendidas como uma racionalização do exercício do poder para constituir práticas de governo sobre a vida.

Pode-se dizer que o "Estado democrático de direito", ao mesmo tempo em que introduziu uma série de políticas e programas sociais nos últimos anos como forma de alargar as possibilidades de acesso aos direitos sociais, ainda que, no momento atual assistimos a um desmonte progressivo dos direitos conquistados, também continuou a produzir movimentos de precarização da vida, violando direitos fundamentais.

A estas violações estão associadas também a contínua criminalização da pobreza, as práticas de extermínio sobre determinadas populações, o aumento das práticas de punição e encarceramento principalmente da juventude negra e pobre, a criminalização das mobilizações populares, dentre outros tantos exemplos, fazem aparecer as práticas de exceção e também o que Scisleski e Bernardes (2014) apontam como sendo uma diversidade de distribuição de acesso aos direitos que nos colocam em diferentes níveis de constituirmo-nos como sujeitos destes direitos. Este modo de funcionamento do Estado nos faz problematizar as políticas públicas de inclusão e as práticas que elas colocam em funcionamento, situando-as no que Foucault (2005a) denomina como tecnologias de governo biopolítico da população, em que a vida enquanto corpo e enquanto espécie passa a ser governada, tornando-se objeto de intervenção estatal. 
Para Foucault (2008b) a preocupação em governar coloca como uma das principais questões a segurança, ou seja, o gerenciamento do que se considera risco na sociedade. Neste artigo, a discussão sobre Estado e políticas públicas parte da política de assistência social, que é considerada um importante meio de acesso aos direitos sociais básicos e que abre um campo de práticas sobre uma população considerada de/em risco. Ao partir da discussão sobre esta política, procura-se problematizar os movimentos de inclusão para colocar em análise os processos de governamentalidade operados pelo Estado a partir do discurso da garantia de direitos, utilizando para isto, o referencial teórico de Michel Foucault, tendo como principal ferramenta de análise 0 conceito de governamentalidade.

Para tanto, buscou-se mapear os itinerários possíveis do sujeito que acessa a rede possibilitada pela Política Nacional de Assistência Social. Este mapeamento e a análise do documento da Política nos levou a considerar nesta discussão dois programas sociais, por ganhar grande centralidade: o programa de distribuição de renda Bolsa Família e o Programa de Atendimento Integral à Família PAIF. A importância destes programas é enunciada na Política Nacional de Assistência Social quando esta afirma que a proteção social deve garantir "segurança de sobrevivência (de rendimento e de autonomia); de acolhida; e, convívio ou vivência familiar" (BRASIL, 2012). Para análise deste campo de estudo utilizaremos como ferramenta o conceito foucaultiano de governamentalidade que nos permite olhar para os possíveis percursos do sujeito de direito da assistência e enxergá-los como estratégias de governo da vida relacionadas com as formas de governar neoliberais.

A noção de governamentalidade que servirá como lente teórica e metodológica, se refere ao processo histórico e contínuo de inserção da vida no domínio político e sua inclusão nos cálculos da racionalidade econômica com a constituição de um Estado e seus mecanismos de segurança para regulação e controle da vida. Remete, portanto, a intervenções não só na vida da população em si, mas nas suas formas de viver. Esta forma de governar emerge com o liberalismo e funciona a partir do jogo entre interesses coletivos e individuais, entre a utilidade social e o beneficio econômico e entre direitos fundamentais e a liberdade (Foucault, 2008a). Nesta perspectiva, o trabalho objetiva analisar itinerários da rede de assistência social, colocando em questão as formas pelas quais a vida passa a ser incluída, governada, analisando a relação entre garantia de direitos e a autonomia dos que são governados. 


\section{A Política de assistência e os itinerários de acesso aos direitos sociais}

A partir da Constituição de 1988 a assistência passa a ser reconhecida como um direito social e passa a trabalhar na lógica da proteção social destinando-se aos sujeitos que se encontram em situações de vulnerabilidade e riscos que são definidos como

famílias e indivíduos com perda ou fragilidade de vínculos de afetividade, pertencimento e sociabilidade; ciclos de vida; identidades estigmatizadas em termos étnico, cultural e sexual; desvantagem pessoal resultante de deficiências; exclusão pela pobreza e, ou, no acesso às demais políticas públicas; uso de substâncias psicoativas; diferentes formas de violência advinda do núcleo familiar, grupos e indivíduos; inserção precária ou não inserção no mercado de trabalho formal e informal; estratégias e alternativas diferenciadas de sobrevivência que podem representar risco pessoal e social (Brasil, 2005, p. 33).

A Política Nacional de Assistência Social - PNAS, é instituída em 2004 e organiza dois níveis de assistência: a proteção básica e a especial. A proteção social básica trabalha de forma preventiva para que situação de violações de direito não ocorram como, por exemplo, o rompimento de vínculos familiares e sociais, situações de violência. Neste nível de atenção, a política trabalha por meio do "desenvolvimento de potencialidades e aquisições no contexto familiar, e o fortalecimento de vínculos familiares e comunitários bem como a integração ao mercado de trabalho" (Brasil, 2004, p. 27). Atua, portanto, na articulação dos eixos família, comunidade e inclusão produtiva e se concretiza através dos Centros de Referência em Assistência Social - CRAS. Nota-se que a prevenção é o que norteia o trabalho da proteção básica, como se estar em uma situação de necessitar acessar a assistência não configuraria um tipo de violação de direitos. A política torna-se, deste modo, o que coloca em discurso o direito de ter direitos sociais básicos.

A proteção especial trabalha, através dos Centros Especializados em Assistência Social - CREAS, com as situações consideradas de direitos violados, especificado pela política como situações em que há violência ou rompimento de vínculos familiares e comunitários, no sentido de desenvolver

estratégias de atenção sociofamiliar que visem a reestruturação do grupo familiar e a elaboração de novas referências morais e afetivas, no sentido de fortalecê-lo para o exercício de suas funções de proteção básica ao lado de sua 
auto-organização e conquista de autonomia (Brasil, 2005, p. 37).

Para o sujeito acessar esta política, ele deve, primeiro, passar por um sistema de cadastramento que mapeará seu perfil sócioeconômico, tendo como foco principal a família. O itinerário, que não é só do sujeito, mas também de sua família, começa com o seu cadastro em uma base de dados do governo federal chamado Cadastro Único, que é uma tecnologia construída para o conhecimento da realidade da população em situação de pobreza e/ou vulnerabilidade social, possível usuária da política pública de assistência. $O$ instrumento obtém informações a respeito do domicílio, família e seus componentes no que se refere a documentação, escolaridade, trabalho e renda, pessoas com deficiência, assim como condições de vida de famílias de grupos específicos, como os de origem indígena, remanescentes de quilombolas e população em situação de rua. Propõe-se a identificar também crianças em situação de trabalho infantil. 0 objetivo é identificar as famílias de baixa renda e inseri-las conforme seu perfil em programas sociais. Uma vez cadastrada, a família passa a ter a possibilidade de adentrar pela rede e tornar-se beneficiária das políticas de inclusão e proteção se satisfizer os critérios de renda instituídos.

Um dos principais programas destinado às famílias da Política de Assistência atualmente é o Programa de Distribuição de Renda - o Bolsa Família. Sobre os usuários deste programa (famílias que possuem renda per capita de 170 reais), uma série de outras intervenções se atrela na construção da rede (Brasil, 2004). O programa de transferência de renda mínima permite um mínimo de condições para que as famílias circulem no mercado de consumo e possam ganhar um mínimo de autonomia para suprir suas necessidades básicas.

Esta inserção vincula a família a um sistema de condicionalidades que exige delas algumas contrapartidas que se referem a uma obrigação da família em manter os filhos estudando, com uma frequência mínima de $85 \%$ para crianças e de $75 \%$ para jovens; comparecer frequentemente ao posto de saúde para pesar, medir e realizar exames, além de manter a vacinação sempre em dia; as gestantes ou mães que amamentam também devem frequentar regularmente o posto de saúde para acompanhamento da saúde da mãe e do bebê após o parto e participar de atividades educativas sobre aleitamento e alimentação saudável; para as famílias em que for identificado risco de trabalho infantil, a família deve garantir uma frequência mínima mensal de $85 \%$ das crianças e adolescentes até 16 anos nos serviços de convivência e 
fortalecimento de vínculos do Programa de Erradicação do Trabalho Infantil.

As condicionalidades deste programa objetivam ampliar o acesso das famílias a serviços como educação e saúde e são entendidas enquanto direito a partir da perspectiva de que a vulnerabilidade das famílias exige um olhar mais cuidadoso sobre elas. Ao mesmo tempo em que ampliam o acesso, inserem as famílias em uma rede de cuidados - e também de controle, passando assim a ser acompanhadas pelos profissionais da rede.

Um programa de grande expressão dentro da PNAS é o Programa de Atendimento Integral à Família - PAIF. O PAIF é um trabalho social com as famílias que busca fortalecer a função protetiva destas por meio de ações que desenvolvam suas potencialidades, autonomia e fortaleçam vínculos familiares e comunitários. O documento da PNAS ressalta que o PAIF foi criado

a partir do reconhecimento de que as vulnerabilidades e riscos sociais, que atingem as famílias, extrapolam a dimensão econômica, exigindo intervenções que trabalhem aspectos objetivos e subjetivos relacionados à função protetiva da família e ao direito à convivência familiar (Brasil, 2012, p. 8).

A Política Nacional de Assistência Social desconstrói a noção de família nuclear enquanto modelo de família e reconhece os novos arranjos familiares modernos. O documento afirma a família enquanto lugar ideal de proteção e com a obrigação de "prover a proteção e a socialização dos seus membros, constituir-se como referências morais, de vínculos afetivos e sociais; de identidade grupal, além de mediadora das relações dos seus membros com outras instituições sociais e com o Estado" (Brasil, 2004, p. 35).

Para que isto aconteça, a rede assistencial se pauta pela noção de matricialidade sociofamiliar. Neste contexto, a família é vinculada a uma rede de proteção que as acompanha no percurso de vida durante sua vinculação com a política de assistência, pois as estratégias de sobrevivência que encontram são consideradas inadequadas e de risco. Esta rede se refere a uma série de medidas que passam a assistir essas pessoas nos mais variados âmbitos da vida: saúde, educação, trabalho e habitação, na perspectiva de intervenção sobre as formas pelas quais elas constroem vínculos entre seus membros e com a comunidade e equipamentos sociais. 


\section{A combinação família-risco como estratégia de privatização do social}

O início do percurso do sujeito da assistência social pela rede aponta para um processo de delimitação da família de/em risco. 0 público que acessa a política é marcado como possuidor de virtualidades inerentes que é preciso controlar e evitar ou comportamentos que é necessário corrigir, normalizar ou incitar por meio da garantia de algumas seguranças.

O sistema de proteção é um efeito da sociedade regida pelos dispositivos de segurança que visa gerir perigos e lidar com aquela população que não se encontra dentro das normas de conduta ou que criam estratégias de sobrevivência nem sempre compreendidas no seu contexto e consideradas socialmente desvalorizadas ou perigosas. Foucault (2008b) afirma que esse tipo de sociedade procura criar um ambiente em função de acontecimentos possíveis, que são séries que precisam ser regularizadas. É a possibilidade para o tratamento daquilo que foge às normas e que vai ser necessário inscrever em um determinado espaço lançando mão de uma série de técnicas de vigilância dos indivíduos e construir diagnósticos sobre eles, classificando suas irregularidades.

A PNAS apresenta o discurso de que determinados arranjos familiares podem engendrar processos de vulnerabilidade e pobreza e que, as desigualdades características da estrutura social aumentam as pressões sobre as famílias que precisam encontrar estratégias alternativas de sobrevivência (BRASIL, 2012). O trabalho com as famílias torna-se central, pois visa estimulá-las a organizar-se como unidade de referência do sujeito e como um lugar de proteção para que ela possa ter as condições necessárias para administrar seus riscos e supostos déficits. Paralelamente a isso, na medida em que se investe na família como local privilegiado para solucionar problemas produzidos por atravessamentos político-econômicos, intensifica-se a lógica de que a família é que deve ser estruturada para não perpetuar o ciclo de vulnerabilidades sociais, delimitando na família as dificuldades.

Scheinvar (2006) discute que o âmbito público, ao fazer-se presente nas relações privadas da família, intervém marcando a hibridação entre o público e o privado e, dessa forma, opera um processo de privatização do social através dessas intervenções.

A política reconhece que a vulnerabilidade é uma produção social, no entanto, há uma tendência em fazer recair sobre a família a responsabilização por sua condição quando diante de uma situação de violência, por exemplo, a família é a primeira a ser acionada, diagnosticada, inserida em programas como os de fortalecimento de vínculo operando um processo de individualização dos 
problemas como se estes fossem resultados de uma suposta desestrutura familiar (Scheinvar, 2006).

Donzelot (1986) pontua que, historicamente, à assistência social foi delegada a necessidade de promover um reerguimento da família, e sobre a classe trabalhadora que começa a se constituir, considerada sem moral e irresponsável e entregue à situação de miséria, recaiu um sistema de disciplinarização para o trabalho e para os bons costumes. Aos poucos, a economia vai se conectando à moralização, produzindo a necessidade de vigilância contínua da família e de observação detalhada de sua vida privada e intervindo de forma a torná-la "agentes recondutores das normas estatais na esfera privada" (p. 58), forjando o sentimento de família nuclear e lugar privado de convivência, os quais hoje naturalizamos.

A partir destas colocações, pode-se pensar que o discurso da garantia de direitos a partir da política pública de assistência social promove uma delimitação e individualização da questão social na família e as intervenções têm uma perspectiva reabilitadora que incidem sobre o comportamento familiar, construindo determinados modos de ser família, inserindo a conduta familiar um uma racionalidade econômica.

\section{A inclusão da vida no contexto neoliberal: a modulação de um sujeito de direito}

As ações que se dirigem às famílias buscando desenvolver sua autonomia por meio de programas de distribuição de renda mínima, inclusão produtiva e fortalecimento de vínculos através de Programas como o PAIF e Bolsa Família, também se constituem em uma tentativa de desenvolver nestas famílias e por meio delas as condições para que possam gerir seus próprios riscos e déficits. 0 desenvolvimento da autonomia é um discurso fortemente presente na política de assistência social. De que autonomia se fala neste contexto?

O que podemos pensar é que os programas e ações neste âmbito, ao mesmo tempo em que oxigenam as vidas ao garantir uma possibilidade de inserção social seja pela renda mínima ou pelos serviços ofertados, trabalha com a pobreza absoluta e não com a pobreza relativa. Ou seja, pode não haver mais pobreza extrema sem que se desmontem os mecanismos de produção de desigualdade. Deste modo, incluir é inserir em uma normalidade, em um ambiente em que é possível regularizar com base em um cálculo de custo e fazer com que estas questões funcionem dentro de um nível considerado ótimo, habilitando a classe trabalhadora a estar dentro do jogo econômico. O autor entende que as estratégias de gestão por parte do Estado não se propõem a 
resolver por completo os problemas sociais, mas torná-los administráveis dentro de uma determinada normalidade (Foucault, 2008b).

Foucault (2001) assinala que o Ocidente conheceu dois grandes modelos de controle dos sujeitos: em um primeiro momento, o modelo da exclusão da lepra e, posteriormente, o modelo inclusivo da peste. O modelo da exclusão da lepra era marcado pelo estabelecimento das diferenças e pela sua separação. Demarcavase a diferença entre doentes e não-doentes, entre os puros e os impuros, para que estes pudessem ser separados daqueles a fim de evitar a contaminação, evitar o rompimento de uma ordem. Esse era um modelo negativo de exclusão, de afastamento, de expulsão. No modelo da peste, que se desenvolve no século XVIII, não se trata mais de rejeitar, mas de delimitar e circunscrever o lugar onde é necessário intervir, implicando uma aproximação do pestífero mediante observações minuciosas.

Quando uma cidade se encontrava em estado de peste, uma série de medidas começava a ser tomada. O território foi dividido em distritos, estes em quarteirões, estes ainda em bairros, e os bairros em ruas. Nas ruas, vigias circulavam para inspeção. O território passa, então, a ser organizado de modo que pudesse ser observado em seus detalhes por um poder contínuo de vigilância. Tudo que era observado era registrado. A cada indivíduo era atribuída uma janela na qual devia mostrar-se quando seu nome fosse chamado. Se não comparecesse, era possível que estivesse de cama, acometido pela peste, sinal de que era preciso intervir. As observações atingiam aquilo que o autor chama de grão fino da individualidade (Foucault, 2001).

Passou-se de uma tecnologia do poder que expulsa, que exclui, que bane, que marginaliza, que reprime, a um poder que é enfim um poder positivo, um poder que fabrica, um poder que observa, um poder que sabe e um poder que se multiplica a partir de seus próprios efeitos (Foucault, 2001, p. 69).

O exemplo da peste é trazido aqui para pensar na forma como a rede de proteção se organiza: primeiro, delimita-se um grupo de risco a partir de um esquadrinhamento da população, considerando-se suas características socioeconômicas. Com esse conhecimento, constroem-se diferentes perfis de necessidades, identificando-se os setores de maiores riscos. Então, inclui-se o grupo de risco em um espaço de proteção que pode ser descrito como uma espécie de quarentena, onde a peste será controlada e vigiada, não com a extirpação da "doença" que acaba por ser individualmente localizada, mas inoculando o vírus para que seja 
possível aumentar os anticorpos a partir de variadas estratégias: distribuição de renda mínima, acesso a serviços básicos, qualificação profissional, orientações e acompanhamento das famílias pelos serviços. Anticorpos necessários para que cada um possa ter mínimas condições para gerir sua vida.

Os programas sociais ao incluir as famílias pelo consumo também incidem sobre a vida das famílias e seus comportamentos que as inserem nos espaços institucionais como forma de qualificar esta inclusão que se quer produtiva, fazendo articular um jogo complexo entre interesses econômicos e direitos fundamentais. Foucault (2008a) aponta que o neoliberalismo introduziu uma forma de governar que incide não nos processos econômicos, mas nos comportamentos em prol destes processos. Os comportamentos são considerados comportamentos econômicos e sobre eles se constituem mecanismos de controle e gerenciamento. Tal forma de governar produz uma forma de subjetivação que incita a autonomia, mas que pode ser entendida como ligada ao que Foucault (2008a) chamou de homo economicus, ou seja, o sujeito que adere por conta própria às ordens do mercado.

Os programas sociais, ao trabalharem com as famílias, visam intervir nos comportamentos e também funcionam como formas de subjetivação porque operam pela via do cuidado potencializando a vida que se quer incluída, fazendo do sujeito e sua relação consigo objetos das práticas de governo.

Nesta perspectiva, a esses movimentos que objetivam incluir, desenvolvendo a potencialidade, fortalecimento de vínculos e autonomia das famílias de/em risco, devem ser analisados não só pelo olhar da conquista de direitos, mas situados como tecnologia de governo neoliberal, que, segundo Passetti (2013), é o tempo das incansáveis capturas através dos dispositivos de inclusão que incidem sobre o sujeito marcado como uma ameaça à ordem sob a condição de "vulnerabilidades" e o fará objeto de investigação para que não venha a tornar-se o criminoso, o vagabundo, o arruaceiro, o traficante, o amedrontador do "bom cidadão".

Agamben (2002) discute a necessidade que o Estado Nação tem de redefinir permanentemente qual a vida humana que pode estar dentro da regra dos direitos. O autor discute que para os direitos humanos, a condição de homem não basta para estar dentro da lógica de direito do Estado Nação. A produção da condição de cidadão é que lhe confere uma atribuição de direitos. Tornar cidadão, ou seja, politizar a vida é, nesta perspectiva, estabelecer uma determinada relação com a norma onde a definição de uma cidadania que passa por critérios que identifica qual é a cidadania que deve ser produzida.

No contexto destas discussões, identificamos uma forma de produzir cidadania atrelada à sociedade de consumo e da inclusão 
produtiva. Deste modo, Passetti (2013, p. 154) afirma que ser cidadão neste contexto, "é um conjunto de deveres para os quais você está apto". Assim, um sistema de proteção, ao garantir direitos a uma população considerada de risco, normaliza o modo como a população circula dentro da rede de proteção para alcançar certo status de cidadania.

A rede de proteção engendrada pelo Estado, ao trabalhar com as famílias, modula o acesso aos direitos a partir de dois movimentos: particularização do problema social na família de/em risco e a qualificação de tais vidas conectado ao discurso da autonomia do homem liberal. Tais práticas de proteção, ao garantirem direitos, qualificam a inclusão que se quer colocar em funcionamento no neoliberalismo.

Partindo destas problematizações torna-se necessário visibilizar a política social não só como conquista de direitos, mas também como estratégia de governamentalidade. A política pública também produz controle e normalização a partir de uma determinada racionalidade econômica. O que é um aparente paradoxo, se revela como forma de governo: ao mesmo tempo em que o Estado garante determinados direitos, também segue como violador destes, quando é incapaz de desmontar as assimetrias de poder que mantém os mecanismos de precarização da vida. A noção de direito, torna-se então, a tradução jurídico-política de determinados interesses, de um determinado tempo.

Para (re)pensar o conceito de autonomia provocado pela Política em questão, torno presente a discussão que Foucault (2006) faz sobre o cuidado de si que é tornar-se sujeito da própria história associado ao cuidado com o outro, que é a possibilidade de se olhar enquanto um sujeito integrado em um tecido social onde suas ações são sempre políticas e têm efeitos na coletividade. Potencializar o "exercício de si" é um constante questionar-se sobre como nos constituímos como sujeito, como somos "assujeitados" por diferentes discursos/práticas.

Quanto ao fortalecimento de vínculos, tão fortemente enunciado na política pública aqui analisada, talvez este possa se construir não como forma de privatização/individualização de um problema social especialmente na família, mas como possibilidade de fortalecer processos de solidariedade e pertencimento comunitário que criem possibilidade de construção de uma atitude crítica.

A crítica é a possibilidade de escapar, transformar, desconfiar, limitar a arte de governar e coloca a positividade do poder em questão, de forma que possamos questionar os efeitos legítimos dos saberes e poderes que fazem com que determinado sistema seja aceito e encontre espaço e que nos faz perguntar sobre como somos governados de determinado modo e como podemos ser governados de outros. É preciso colocar em questão as formas 
pelas quais produzimos verdades e, por estas, somos assujeitados e governados (Foucault, 2005b). É possível promover autonomia diferente da autonomia do homem liberal - sem produzir práticas de controle e sujeição a partir da política pública?

\section{Referências}

Agamben, G, (2002). Homo Sacer: o poder soberano e a vida nua I. Belo Horizonte: Ed. da UFMG.

Brasil. (2005). Ministério do Desenvolvimento Social e Combate à Fome. Secretaria Nacional de Assistência Social. Política Nacional de Assistência Social - PNAS/2004; Norma Operacional Básica - NOB/Suas.

Brasil. (2012). Ministério do Desenvolvimento Social e Combate à Fome. Secretaria Nacional de Assistência Social. Orientações Técnicas sobre o PAIF: O Serviço de Proteção e Atendimento Integral à Família - PAIF, segundo a Tipificação Nacional de Serviços Socioassistenciais. Diário Oficial da União.

Donzelot, J. (1986). A polícia das famílias. 2aㅡ ed. Rio de Janeiro: Graal.

Foucault, M. (2001). Os anormais. São Paulo: Martins Fontes.

Foucault, M. (2005a). Aula de 17 de março de 1976. In M.

Foucault. Em defesa da sociedade: Curso no Collège de France. São Paulo: Martins Fontes.

Foucault, M. (2005b). O que é a crítica? [Crítica e Aufklärung]. Relatório da sessão de 27 de maio de 1978. In F. L. Britto. Crítica e modernidade em Foucault: uma tradução de “Qu'estce que la critique? [Critique et Auflärung]", de Michel Foucault (pp. 35-63) (Dissertação de Mestrado). Universidade Estadual do Rio de Janeiro, Rio de Janeiro, RJ, Brasil.

Foucault, M. (2006). A Hermenêutica do Sujeito. São Paulo: Martins Fontes.

Foucault, M. (2008a). O nascimento da biopolítica. São Paulo: Martins Fontes.

Foucault, M. (2008b). Segurança, território e população. São Paulo: Martins Fontes.

Passetti, E. (2013). O carcereiro que há em nós. In: A. M. C. Ximendes, C. Reis \& R. W. Oliveira (Orgs.). Entre garantia de direitos e práticas libertárias (pp. 147-181). Porto Alegre: Conselho Regional de Psicologia do Rio Grande do Sul.

Scheinvar, E. (2006). A família como dispositivo de privatização do social. Arquivos Brasileiros de Psicologia, 58(1), 48-57.

Scisleski, A. C. C., \& Bernardes, A. G. (2014). Sobre Foucault e Agamben: uma reflexão sobre subjetividade, ética e Políticas Públicas. Estudos de Psicologia (Natal), 19(2), 128-137. 


\section{Endereço para correspondência \\ Karen Cristina Cavagnoli}

Universidade Federal do Rio Grande do Sul

Departamento de Psicologia

Av. Ramiro Barcelos, 2600, Santana, CEP 90035-003, Porto Alegre - RS, Brasil

Endereço eletrônico: karenzotti@yahoo.com.br

\section{Neuza Maria de Fátima Guareschi}

Universidade Federal do Rio Grande do Sul

Departamento de Psicologia

Av. Ramiro Barcelos, 2600, Santana, CEP 90035-003, Porto Alegre - RS, Brasil

Endereço eletrônico: nmguares@gmail.com

Recebido em: 08/03/2016

Reformulado em: 23/06/2017

Aceito em: 08/08/2017

\section{Notas}

* Psicóloga, Mestre pelo Programa de Pós Graduação em Psicologia Social e Institucional pela Universidade Federal do Rio Grande do Sul - UFRGS. Possui especialização em Saúde da Família e Comunidade pelo Programa de Residência Integrada em Saúde do Grupo Hospitalar Conceição.

** Possui graduação em Psicologia pela Pontifícia Universidade Católica do Rio Grande do Sul (1979), mestrado em Psicologia Social e da Personalidade pela Pontifícia Universidade Católica do Rio Grande do Sul (1991). Doutorado em Educação - University of Wisconsin-Madison (1998). Pós-doutorado no Institute of Education na University College of London (2014). Atualmente é professora adjunta da Universidade Federal do Rio Grande do Sul (UFRGS). Coordena o grupo de pesquisa Estudos Culturais e Modos de Subjetivação e o Núcleo E-politcs - Estudos em Políticas e Tecnologias Contemporâneas de Subjetivação. Desenvolve estudos na linha de pesquisa Políticas Públicas, Trabalho, Saúde e Produção de Subjetividade.

Este artigo de revista Estudos e Pesquisas em Psicologia é licenciado sob uma Licença Creative Commons Atribuição-Não Comercial 3.0 Não Adaptada. 